\title{
Cloudy with a chance of feelings: Affective forecasting as a resource for situation selection across the lifespan
}

Victoria A. Floerke ${ }^{1}$, Molly Sands ${ }^{2}$, Derek M. Isaacowitz ${ }^{2}$, Ayanna K. Thomas ${ }^{1}, \&$ Heather L. Urry ${ }^{1}$

${ }^{I}$ Department of Psychology, Tufts University, Medford, MA, U.S.A.

${ }^{2}$ Department of Psychology, Northeastern University, Boston, MA, U.S.A.

Correspondence concerning this article should be addressed to Heather Urry, Department of Psychology, Tufts University, 490 Boston Avenue, Medford, MA 02155. E-mail:

Heather.Urry@tufts.edu.

Word count: 7907 


\title{
Cloudy with a chance of feelings: Affective forecasting as a resource for situation selection across the lifespan
}

\begin{abstract}
Despite the importance of emotion regulation (ER) to physical and psychological health, little is known about the resources that contribute to ER success. In two studies, we tested the hypothesis that affective forecasting, or the ability to predict how situations will make one feel, would be associated with situation selection, an ER strategy in which one chooses situations based on their emotional potential. In Study 1, 53 younger adults completed behavioral assessments of both affective forecasting and situation selection. Contrary to our predictions, there was no robust support for the hypothesis. However, a number of design limitations may have obscured the hypothesized association. Thus, we conducted a second study to retest the hypothesis after instituting several improvements in measurement and timing. In addition, we sought to test a new hypothesis that the association between affective forecasting and situation selection would vary by age. In Study 2, 54 younger and 50 older adults completed behavioral assessments of affective forecasting and situation selection. Analyses indicated that making fewer forecasting errors was associated with selecting fewer emotional relative to neutral situations. No robust age differences were found. This pattern suggests that affective forecasting may be a resource for situation selection across the lifespan.
\end{abstract}

Keywords: situation selection; affective forecasting; SOC-ER; aging

The last two decades have seen a dramatic increase in the number of papers devoted to understanding emotion regulation (ER), a heterogeneous set of processes that influence the type, frequency, and intensity of the emotions people experience. The increase of interest in scholarly attention likely represents the oft-cited view that ER is essential to daily functioning, presumably because effectively managing one's emotions is conducive to meeting one's goals. According to the process model of emotion regulation (Gross, 1998), there are many family of strategies one can use to regulate an emotional experience during the emotion-generative cycle, including situation selection, situation modification, attentional deployment, cognitive change, and response modulation (Gross, 1998). 
With such an extensive set of ER options, one might reasonably wonder which option is apt to be most effective for a given person in a given situation? Although popular psychotherapies like cognitive behavioral therapy (CBT) presume that cognitive change changing how one thinks about an emotional response - is the most effective ER strategy, the Selection, Optimization, and Compensation with ER (SOC-ER; Urry \& Gross, 2010) framework suggests that ER success depends upon selecting particular ER strategies, optimizing these different emotion regulatory strategies in response to particular emotion-eliciting events, and compensating with different ER strategies in the face of ER failure.

Perhaps the most important theoretical contribution of SOC-ER is its suggestion that individuals select and optimize particular ER strategies based on the resources available to them. Resources help make a specific emotion regulation strategy possible, and can be either internal (e.g., working memory capacity, perspective taking) or external (e.g., social support; Opitz, Gross, \& Urry, 2012; Urry \& Gross, 2010). While little is known about how specific resources contribute to ER success, some ER strategies might require fewer resources than others (Opitz, Gross, \& Urry, 2012); situation selection might be one such strategy.

\section{Situation selection}

Situation selection is an ER strategy in which one picks situations in order to evoke particular emotions; it represents the first opportunity an individual has to engage in ER (Gross, 1998; Urry \& Gross, 2010). Accordingly, it may require fewer cognitive resources than other strategies because it involves individuals proactively managing an emotion before it even begins (Gross \& Thompson, 2007).

Until recently, very few studies in the emotion regulation literature to date have focused 
on situation selection (e.g., Rovenpor, Skogsberg, and Isaacowitz, 2013; Vujović, Opitz, Birk, \& Urry, 2014; Livingstone \& Isaacowitz, 2015; Sands \& Isaacowitz, 2016). In one of few examples, Vjuović and colleagues (2014) demonstrated that individuals tend to be motivated to terminate the situation they're in when they're upset by high-arousal (relative to low-arousal) negative stimuli, as well as when they're bored by low-arousal (relative to high-arousal) neutral stimuli.

Otherwise, the scant research that has been conducted has mainly concentrated on determining whether there are age differences in this form of emotion regulation. For example, Rovenpor et al. (2013) found that older adults with high self-efficacy and general control beliefs tend to choose to watch and read fewer negative stimuli, whereas younger adults with high selfefficacy and general control beliefs tend to choose to watch and read more negative stimuli. More recently, Livingstone and Isaacowitz (2015) found that older adults typically choose to spend less time interacting with negative stimuli than younger adults. However, their other work suggests that, when participants have free rein to attend to stimuli varying in valence, younger and older adults deploy their attention towards similar proportions of valenced stimuli (Isaacowitz, Livingstone, Harris, \& Marcotte, 2015), and that age differences in arousal preferences may instead be more influential in driving selective emotion regulatory behavior (Sands, Garbacz, \& Isaacowitz, 2016).

So far, the limited research on situation selection suggests that people choose situations as a function of both their valence and arousal. However, these studies are largely silent about what resources make it likely that participants will engage in situation selection. Until the resources that drive successful situation selection are known, situation selection cannot be effectively modulated. One possible resource for situation selection is affective forecasting 
ability (Urry \& Gross, 2010).

\section{Affective forecasting}

Affective forecasting refers to the process of predicting how a given situation will make one feel before actually experiencing it (see Gilbert, Pinel, Wilson, Blumberg, \& Wheatley, 1998). If individuals are good at predicting their emotions, they might use their forecasting ability as a resource for selecting situations that help them achieve their emotional goals.

People tend to be poor at predicting how they will feel (see Gilbert, 2007, for a review). Individuals tend to either overestimate or underestimate how good or how bad they will feel after particular events. For instance, individuals tend to be less upset than they forecast they would be (e.g., they feel less negatively after a seronegative HIV test than they expected they would feel; Sieff, Dawes, \& Loewenstein, 1999). While one might be inclined to believe experience would make people wiser, affective forecasts for familiar events are neither easier to make nor more accurate than they would be for novel events (Ayton, Pott, \& Elwakili, 2007).

Although individuals tend to overestimate how good or bad they will feel (this is known as absolute forecasting — or the difference between actual and predicted affect), they are pretty good at relative forecasting (or the correlation between actual and predicted affect). Specifically, those individuals who believe they will be the most affected actually are the most affected (Mathieu \& Gosling, 2012). There have also been reports of age differences in affective forecasting (e.g., Nielsen, Knutson, \& Carstensen, 2008), whereby older adults seem less likely than younger adults to make certain kinds of affective forecasting errors.

Many empirical studies concerning affective forecasting have focused on individuals' 
affective predictions for relatively significant life events, as well as those occurring farther in the future. Fewer studies have examined forecasts made about more commonplace events over briefer time frames (e.g., Nielsen, Knutson, \& Carstensen, 2008; Pearmana, Andreoletti, \& Isaacowitz, 2010). One exception of note had participants forecast how they would feel while completing a monetary incentive delay task right before they actually completed said task, and then observing their actual and recalled affect (Nielsen et al., 2008).

\section{Age as a possible moderator of affective forecasting and situation selection}

Based on existing scholarship, it's possible that age may play a moderating role in the potential link between situation selection and affective forecasting. For example, it's been proposed that older adults might be better at some types of ER than younger adults, and that this difference might be resource driven (Urry \& Gross, 2010). Moreover, as noted in the previous section, older adults make fewer errors in forecasting subsequent arousal than younger adults (Nielsen, Knutson, \& Carstensen, 2008). Perhaps older adults are, thus, better at using situation selection because they have more of the necessary resource (the ability to accurately forecast experienced arousal). Indeed, recent theory suggests older adults might benefit from utilizing situation selection more than other ER strategies because it can help them dampen undesirable physiological arousal (Charles, 2010), or even prevent it before it arises. So, if older adults are good at forecasting when they might experience unwanted arousal (Nielsen et al., 2008), an association between these two constructs seems plausible. If such a link were found, it would suggest that affective forecasting is a resource for situation selection. It would also explicate why situation selection sometimes but not always varies with age, putatively due to individual differences in resource availability. 


\section{The present studies}

The authors are unaware of any studies examining whether affective forecasting ability is associated with the situations one chooses to experience, nor how the relation between these constructs varies across the lifespan. Redressing this limitation of the extant literature, in this paper, we present two studies designed to 1) ascertain whether affective forecasting ability is associated with situation selection, and 2) whether there is an age-related change in this association. The findings and limitations of Study 1 motivated the design of Study 2.

\section{Study 1}

The aim of Study 1 was to determine whether affective forecasting ability is associated with situation selection. Participants completed both an affective forecasting task and a situation selection task. Based on prior research, we surmised that there would be individual differences in people's affective forecasting ability, such that some individuals would make relatively small errors when predicting their affect while other individuals would make relatively large errors when predicting their affect. We expected these individual differences, in turn, to be linked with differences in situation selection use. We hypothesized that making fewer errors in an affective forecasting task would be associated with making more emotion-driven decisions in the situation selection task (e.g., choosing more or less negative or positive situations relative to neutral ones).

\section{Method}

\section{Participants}


Participants $(N=61)^{1}$ were recruited from the Tufts University recruitment pool (Sona Systems, Ltd.) and the surrounding community. Of the 61 participants recruited, 53 completed the experiment without any technical issues and are included in the final sample (see Table 1). Individuals received either course credit or monetary compensation (\$15/hour) for their participation. All participants provided written informed consent. The Social, Behavioral, and Educational Research Institutional Review Board at Tufts University and the U.S. Army Human Research Protections Office approved of both the Study 1 and Study 2 protocols in their entirety.

\section{Materials $^{2}$}

\section{Affect ratings}

To measure affective state, participants completed a 12-item self-report scale measuring positivity, negativity, and arousal. It was adapted from previous work (Tamir, John, Srivastava, \& Gross, 2007). Using this measure, participants rated how they were currently feeling, and how they forecasted they would feel and wanted to feel at a specific future time point, across a variety of items at multiple time points. An example positive mood item is "happy, pleased, contented", an example negative mood item is "sad, depressed, down", and an example arousal item is “active, alert, keyed up". Participants rated each item on a 7-point Likert scale $(1=$ not very much, $7=$ very much). The composite positive, negative, and arousal subscores were derived from the items' face validity and via principal components analysis.

1. We anticipated needing $\sim 50$ participants for analysis so we recruited 10 additional on the assumption that we would lose some data due to technical issues. With $\mathrm{N}=53$, we had $80 \%$ to detect two-tailed correlations of $r=.37$ or higher based on a sensitivity analysis in the R package, pwr 1.2-1 by Champely et al. https://CRAN.R-project.org/package=pwr

2. A number of physiological measures, post-task questionnaires, trait questionnaires, and eye tracking measures not relevant to the central hypotheses were also collected throughout the course of the study. Please refer to the appendix for more specific information about each of these measures. 


\section{Affective forecasting task}

Since studies examining affective forecasting in the context of commonplace events have varied considerably in their design, we sought to develop a new paradigm that allows one to examine how affective forecasting is associated with emotion regulation behaviors, in this case, situation selection. The paradigm needed to provide a context in which participants could make affective forecasts about a specific laboratory event before they actually experienced it. For this reason, we used a modified version of the Trier Social Stress Test (TSST; Kirschbaum, Pirke, \& Hellhammer, 1993).

In our variant of the TSST, participants first received brief yet detailed descriptions (see Appendix) of the two traditional tasks of the TSST, which concern giving a speech and performing mental arithmetic, respectively. These two descriptions were meant to provide participants with sufficient information about the tasks such that they could make affective forecasts about how they thought they would feel while completing them without actually having to expose them to the tasks themselves.

After reading each description, participants contemplated how they would feel during the task in question for a period of thirty seconds. After the deliberation period, participants made predictions of how positively, negatively, and aroused they would feel using the aforementioned affect ratings. Participants completed this process twice, separately for the speech and math portions of the test. Next, participants completed a crossword puzzle for a period of five minutes as a distractor to reduce the impact of participants' affective forecasts on their actual affect ratings. After finishing the crossword, participants completed both Trier tasks in a randomized 
order. After each of the tasks, participants' self-reported positivity, negativity, and arousal ${ }^{3}$.

One can forecast that one will feel more or less intensely than one actually does. As we had no a priori reason to expect that the direction of the forecasting errors would matter for our hypothesis, we computed the absolute value of the difference between participants' actual and forecasted affect as our measure of forecasting error. Consequently, individuals whose score approached zero had low affective forecasting error and individuals whose score deviated from zero had higher forecasting error. Participants' affective forecasting error scores ranged from 0-

6.

Situation selection task

To assess situation selection behaviors, participants completed a modified version of the Affective Environment (AE; e.g., Isaacowitz et al., 2015; Rovenpor et al., 2013). First, participants rated how they wanted to feel in approximately 10 minutes (i.e., immediately after the situation selection task) before we described the AE task. We then told participants that they would have the opportunity to view a series of videos, and subsequently directed them to a home screen with thumbnails briefly depicting the positive, neutral, and negative videos of either low or high arousal that they could choose to view (see Figure 1). The order in which the valence of these items was presented on the home screen was counterbalanced across participants. For a fixed 10-minute interval, participants were allowed to watch whichever videos they wished, based on the valence and arousal information provided. Importantly, we told participants that,

3. Supporting the stressful nature of the TSST, participants' self-reported negative and arousal affect, as well as their physiological responding (heart rate, skin conductance), significantly increased from baseline during both TSST tasks. Participants' self-reported positive affect significantly decreased from baseline during the TSST. 
should they wish to stop viewing a video, they could press the spacebar at any time to be redirected to the home screen.

After 10 minutes, participants again provided self-reported affect ratings. The number of positive, negative, and neutral items participants chose, as well as the ratios of positive-to-neutral and negative-to-neutral videos, served as indexes of situation selection behavior. Individuals receiving higher scores thus exhibited a stronger preference to select emotional situations with greater relative frequency than neutral situations. However, not all participants watched a neutral video; since one cannot divide by zero, participants who did not watch a neutral video have neither positive-to-neutral nor negative-to-neutral scores.

\section{Procedure}

After consenting to participate in the study, we administered a neutral baseline task through EPrime software (Psychology Software Tools, Pittsburgh, PA) to ascertain state levels of affective responding. Participants simply sat quietly and observed a fixation cross for a period of two minutes, after which they reported how positively, negatively, and aroused they felt.

Once the baseline task was completed, participants completed the affective forecasting and situation selection tasks in a counterbalanced order. Participants then watched a comedic video clip to help alleviate any temporary stress, anxiety, and negativity that accrued during the laboratory session. Finally, participants were debriefed and compensated for their time.

\section{Results}

Preliminary Analyses 
Did participants make errors when forecasting how they would feel?

To ascertain whether participants were successful at forecasting how they would feel (positive, negative, aroused) during the two tasks of the TSST, a series of one-sample t-tests were conducted against a test value of 0 . Using the |actual - forecasted affect $\mid$ equation, a test value of 0 would indicate no forecasting error (e.g., no difference between predicted affect and actual affect; refer to Table 2 for means of each of these results).

Analyses revealed that mean affective forecast errors deviated significantly from 0 for feeling positive, $t(52)=7.32, p<.001$, negative, $t(52)=6.86, p<.001$, and aroused, $t(52)=$ 8.47, $p<.001$, affect. Participants therefore largely erred at forecasting both the valence and arousal of their experience of the TSST.

What videos did participants choose to watch?

Table 2 provides a breakdown of the number of videos participants watched within each video type. Participants watched more neutral than positive, $t(52)=-2.11, p<.05$, and negative, $t(52)$ $=-2.72, p<.01$, videos. This suggests that, as a sample, participants gravitated away from emotional material within the situation selection task.

\section{Hypothesis Testing}

Is affective forecasting error related to participants' situation selection behaviors?

To answer this question, we conducted two multiple regressions with absolute affective forecasting error for feeling positive, negative, and aroused entered as simultaneous predictors of the positive-to-neutral or negative-to-neutral ratio of videos watched in the affective environment 
(see Table 3). Analyses revealed only one significant association out of six possible. Thus, contrary to our hypotheses, there was no robust association between affective forecasting ability and the extent to which people selected situations based on emotional valence in Study 1. See Table 4 for a series of bivariate Pearson product-moment correlations between all of the predictor and criterion variables used in these multiple regression analyses.

\section{Discussion}

The purpose of this study was to ascertain whether individuals who make fewer affective forecasting errors in one context would be more likely to select situations based on their emotional potential in another context. While results indicated that individuals made relatively high errors when predicting how positively, negatively, and aroused they would feel about the speech and math tasks, there was little evidence of the hypothesized association between affective forecasting ability and situation selection defined as choosing emotional (relative to neutral) content in the affective environment task.

Consistent with previous work, individuals do seem to be make errors when forecasting how they're going to feel in a given situation, across both valence and arousal domains. Since this study's affective forecasts were rooted in more commonplace, immediate situations than the significant, longer-term situations that are typically studied (e.g., how one will feel when one gets tenure, gets married, etc.), this finding contributes to the growing body of evidence that people are unsuccessful at predicting their affect in any situation, not just in the face of relatively major, distal life events.

This study represents an attempt to begin exploring uncharted territory concerning the relation between affective forecasting and situation selection. The tasks we used strike us as 
promising means by which one can index affective forecasting and situation selection behaviors, respectively. However, despite this study's novelty, it was not without limitations. Importantly, the modified tasks utilized to index both affective forecasting and situation selection have not previously been used as they were described in this study. It may be that the tasks are not yet optimized to operationally define affective forecasting and situation selection for use in this context. Within the affective forecasting task, perhaps there was insufficient time between when participants made forecasts of their affect and when they self-reported their actual affect during the two tasks that comprise the TSST; though preliminary analyses suggested that the sample as a whole was inaccurate at predicting affect, it's possible that some participants remembered their forecasted affect ratings when making ratings of their actual affect. During the situation selection task, participants were only able to choose up to two videos within each valence category, which may not have afforded sufficient variation to reveal the effects of interest. The task also allowed participants to view thumbnails of the videos they could choose to watch, as well as to stop watching videos whenever they wished to stop viewing them. Ending a video might, arguably, be more of an example of situation modification, a related ER strategy that may rely upon different resources than situation selection (Urry \& Gross, 2010; cf. Vujović et al., 2014). Moreover, viewing different affective elements of the thumbnails could be construed as attentional deployment, yet another ER strategy relying on different resources than either situation selection or situation modification (Urry \& Gross, 2010). Future work should attempt to disentangle situation selection from situation modification and attentional deployment by preventing people from ending videos they watch and not providing thumbnail images for each video. Finally, the reliability of ratings of arousal across tasks were low, probably largely due to the low number of items comprising that subscale (two). Future work should use mood rating scales that maximize 
reliability and, thus, the ability to test hypothesized relations between affective forecasting and situation selection.

In light of the discussion above, one goal of Study 2 was to address our research question in a way that would retain key strengths of Study 1 - use of controlled tasks to measure individual differences in affective forecasting and situation selection - while at the same time instituting improvements to address many of its aforementioned limitations. In addition, given the possibility that links between affective forecasting and situation selection might differ in younger and older adults, we sought to extend Study 1 by investing cross-sectional age as a critical predictor in Study 2, to which we now turn.

\section{Study 2}

One of the limitations of Study 1 was the potentially insufficient delay between when participants forecasted their affect and when they made self-reported ratings of their actual affect. Consequently, participants in Study 2 completed an affective forecasting task in which they made affective forecasts online one week prior to their laboratory session. Additionally, all participants watched the same set of videos at the end of the situation selection task for which they made forecasts during the affective forecasting task one week prior. Participants' actual affect in response to these videos was obtained immediately after each one was viewed.

Another limitation of Study 1 was that there might not have been a sufficient number of video clips to choose from in the situation selection task. Study 2 therefore included twice as many videos as Study 1, four each of positive, negative, and neutral videos, two low and two high arousal for each valence category. Relatedly, Study 2 also attempted to minimize the likelihood that participants were using other ER strategies (specifically, attentional deployment 
and situation modification) during the task.

Finally, to assess whether the association between affective forecasting ability and situation selection varies across the lifespan, we recruited both younger and older adults for Study 2. The age-related differences in arousal forecasting found in previous work (Nielsen et al, 2008) suggest that, if there is an association between affective forecasting ability and situation selection, older adults might be better at selecting situations based on their emotional potential. Indeed, while findings in this domain are somewhat mixed, there's evidence that younger adults might prefer negative material more than older adults, and perhaps even that older adults might prefer positive material more than younger adults (Mather \& Carstensen, 2005; Murphy \& Isaacowitz, 2008). Study 2 made it possible to compare the two age groups on these metrics (specifically, whether older adults are more likely to select positive relative to neutral situations, and whether younger adults are more likely to select negative relative to neutral situations).

We hypothesized that participants with fewer forecasting errors would select videos within the situation selection task more based on emotional valence. Based on age differences in preferences for emotional information, we further hypothesized that younger adults who made fewer forecasting errors would select more negative (relative to neutral) videos in the situation selection task, whereas older adults with fewer forecasting errors would select more positive (relative to neutral) videos.

\section{Method}

\section{Participants}


Participants aged 18-30 $(N=56)$ and 65-77 $(N=53)^{4}$ years were recruited from Tufts University (including Tufts University's Aging Research Registry facilitated by The Cognitive Aging and Memory Lab) and the greater Boston metro area. Being within one of the age ranges was the only requirement for study participation. Due to technical issues, 54 younger and 50 older adults were retained for analyses (see Table 5). They either received course credit or monetary compensation ( $\$ 5$ for day 1 and $\$ 15 /$ hour for day 7) for participating. All participants provided online informed consent on day 1 , and assented to their continued participation on day 7 .

\section{Materials $^{5}$}

\section{Affect ratings}

We collected affect ratings using an adapted Evaluative Space Grid (Larsen, Norris, McGraw, Hawkley, \& Cacioppo, 2009). The adapted ESG asked participants to rate predicted and actual positive and negative affect $(1=$ not at all, $5=$ extremely $)$. To index arousal, we calculated the mean of the positive and negative ratings. Participants filled out this questionnaire at multiple time points throughout Study 2. We used a different measure than the one used in Study 1 to accommodate more measurement occasions.

\section{Affective forecasting task}

Because older adults are not affected by the TSST in the same way that younger adults are

4. With $\mathrm{N}=104$, we had $80 \%$ power to detect two-tailed correlations of $r=.27$ or higher in the whole sample, $r=.38$ or higher within the smaller of the two age groups $(\mathrm{N}=50)$, and mean differences between groups of Cohen's $d=.56$ or higher based on a sensitivity analyses in the R package, pwr 1.21 by Champely et al. https://CRAN.R-project.org/package=pwr

5. As in Study 1, several other measures, including post-task questionnaires, trait questionnaires, eye tracking, and indices of peripheral physiology not relevant to the central hypotheses were also collected throughout the course of Study 2. Please refer to the appendix for more information. 
(Kudielka, Buske-Kirschbaum, Hellhammer, \& Kirschbaum, 2004), we devised a modified affective forecasting task. Affective forecasting was assessed by asking participants to make affective forecasts based on short descriptions ( $<10$ words; see Appendix) of three video clips, one neutral, one positive, and one negative, one week ahead of their laboratory session. We did this because it mitigated the likelihood that there was insufficient time between when participants forecasted their affect and when they reported on their actual affect. Unlike in Study 1, participants were not told that they would actually be watching these three videos in the laboratory session.

At the end of the situation selection task in the laboratory session, which will be described below, participants watched the neutral clip, and then the positive and negative video clips in randomized order. They then rated how positively and how negatively they actually felt while watching each of those videos.

The operationalization of forecasting error remained unchanged from Study 1. Participants' affective forecasting error scores ranged from 0-4.

\section{Situation selection task}

We again used a modified version of the AE task (Rovenpor et al., 2013; Isaacowitz et al., 2015) in this study. The primary changes concerned adding twice as many videos to the task (totaling 12), and removing the thumbnail information in favor of having participants just select their situations based on labels that provided valence and arousal information. Importantly, we used videos that received comparable ratings of valence and arousal by younger and older adults based on previous pilot testing. 
Like in Study 1, participants rated their desired affective state in approximately 25-30 minutes before receiving task instructions. We then told participants that they would have carte blanche to watch a series of videos ${ }^{6}$, and were subsequently directed to a home screen. The home screen provided valence and arousal information for each video. It also showed how many videos remained for selection within each category and in the task overall (see Figure 2). The valence order of these items was counterbalanced across participants within each age group, as in Study 1.

Unlike in Study 1, once Study 2 participants committed to watching a certain video, they watched it in its entirety. After viewing each video, participants rated how they felt, and indicated whether or not they had seen the video before. The ratio of positive-to-neutral and negative-to-neutral videos selected again served as indexes of the extent to which they selected situations based on emotional valence.

\section{Procedure}

After responding to study advertisements, all participants received an email with the link to a Qualtrics survey. In that survey, they provided online informed consent and made ratings to forecast how they would feel while watching the target neutral, positive, and negative video clips, which they would ultimately watch after the situation selection task in the lab.

One week later, participants came into the laboratory. Participants first completed the

6. Participants were given extensive instructions about how to complete this task, using an approximately 10-minute long training paradigm and follow-up Q\&A. Importantly, participants were told they could watch whichever 6 of the 12 videos they wanted, a constraint we hoped would encourage participants to be more selective about the videos they would watch based on the valence and arousal information provided. 
neutral baseline task used in Study 1. Participants then completed the situation selection task. After watching their chosen videos, participants then watched the target videos for which they provided affective forecasts a week prior, and provided ratings of their actual affect at the end of each. The experiment concluded in the same manner as in Study 1.

\section{Results}

\section{Preliminary Analyses}

Did participants make errors when forecasting how they would feel?

As in Study 1, analyses revealed that mean affective forecasts deviated significantly from 0 when predicting how negatively, $t(103)=23.38, p<.001$, how positively, $t(103)=25.94, p<.001$, and how aroused, $t(103)=21.91, p<.001$, they would feel while watching the positive, negative, and neutral videos. Participants were therefore relatively unsuccessful at forecasting their feelings. See Table 6 for mean forecasting errors by group.

What videos did participants choose to watch?

Table 6 provides a breakdown of the number of videos participants watched within each video type. A 3x2 ANOVA revealed that younger and older adults watched the same number of positive, negative, and neutral videos ( $p$ s $>.3$ ). Regardless of age, participants approached the situation selection task with a hedonic goal, at least in terms of the number of positive (relative to neutral) videos they chose.

\section{Hypothesis Testing}

Is affective forecasting error related to participants' situation selection behaviors? 
To assess whether affective forecasting error was associated with situation selection behaviors, we conducted multiple regression analyses with participants' absolute affective forecasting error (positive, negative, arousal) entered as continuous predictors of situation selection behaviors (positive-to-neutral, negative-to-neural). Table 7 depicts the results of these multiple regression analyses. The three affective forecasting error variables explained a significant amount of the variance in the ratio of positive-to-neutral videos watched in the situation selection task; however, none of the forecasting variables were uniquely associated with the ratio (all $p \mathrm{~s}>.1$ ). The three affective forecasting error variables did not explain a significant amount of variance in the ratio of negative-to-neutral videos watched in the situation selection task. Thus, contrary to the hypotheses, there was little evidence to suggest associations between affective forecasting error and situation selection behavior in Study 2. See Table 8 for bivariate Pearson productmoment correlations between all of the predictor and criterion variables used in these analyses.

Do younger and older adults differ in their affective forecasting error and subsequent situation selection behaviors?

We conducted a hierarchical multiple regression to evaluate whether the association between affective forecasting error and situation selection behaviors differed as a function of age. We entered absolute affective forecasting error (positive, negative, arousal) as a step 1 continuous predictor, age $(1=$ old, $0=$ young $)$ as a step 2 categorical predictor, and their interactions (positive forecasting error*age, negative forecasting error*age, and arousal forecasting error*age) as continuous step 3 predictors; situation selection behaviors (positive-to-neutral, negative-to-neutral) were the criterion variables. There were no associations between age, absolute affective forecasting error, or their interactions on the ratio of positive-to-neutral ( $p$ s $>$ .05 ) or negative-to-neutral videos watched (all $p \mathrm{~s}>.1$ ). There was, thus, no indication that the 
association between affective forecasting error and situation selection behaviors is moderated by age.

\section{Exploratory Analyses}

It was possible that our inability to detect an association between affective forecasting error and situation selection in both Studies 1 and 2 was a function of how we were operationalizing affective forecasting error and situation selection. Thus, we examined different operationalizations of each. To do this, we used MPlus (Version 7.4; see Muthén \& Muthén, 1998-2015) to test several models, using full information maximum likelihood estimation with robust standard errors. We used confirmatory factor analyses in an attempt to create an affective forecasting latent variable comprised of positive, negative, and arousal forecasting factors (Study 1) and positive and negative forecasting factors (Study 2). For situation selection, we created computed two new subtractive contrasts. One was an index of hedonic preference, defined as the difference between the number of positive videos (1) watched and the number of negative videos (-1) watched. The other was an index of emotional preference, defined as the difference between the number of emotional videos watched ( 1 for positive, 1 for negative) and the number of neutral videos (-2) watched.

Based on the model fit information, we chose to jettison the affective forecasting latent variable in favour of an affective forecasting error average variable, which was comprised of the means of the positive, negative, and arousal forecasting variables (Study 1) and the means of the positive and negative forecasting variables (Study 2; see Tables 9a and 9b). Even with this more parsimonious affective forecasting error composite, there were no significant associations between any of the affective forecasting error scores and hedonic preference in either Study 1 or 
2. There also was no association between the affective forecasting latent variable and emotional approach in Study 1. However, there was a strong association between the average of the positive and negative affective forecasting error variables and emotional preference in Study 2 (see Figure 3). Making fewer forecasting errors was associated with selecting fewer emotional relative to neutral situations. We found no age difference $(p=.35)$.

\section{Discussion}

Study 2 improved upon the design of Study 1 by assessing whether affective forecasting ability was associated with situation selection. Study 2 also extended Study 1, by discerning whether the association between affective forecasting ability and situation selection behaviors varied as a function of age. Tests of the original hypothesis showed that affective forecasting error was not robustly associated with situation selection, but exploratory analyses with different operationalizations of the two constructs provided tentative evidence that affective forecasting error is associated with avoiding emotional situations. However, the hypothesized age differences in the association between affective forecasting and situation selection did not emerge.

The Study 2 design represented an extensive overhaul of both the materials and procedures utilized in Study 1. The additional time point, the increased potential range of videos available in the situation selection task, and the decision to examine both younger and older adults simultaneously all aided the examination of whether affective forecasting success was associated with subsequent situation selection behaviors, as well as whether this association varies across the lifespan. Nevertheless, Study 2 was not without shortcomings. For one, it's possible that measuring how one predicts one will feel after watching a video clip is not the best 
way to capture affective forecasting ability; participants may be insufficiently motivated to make accurate forecasts for such a decontextualized hypothetical event, one that they weren't even told that they would experience. Moreover, our focus on forecasting error as a difference score means that this study doesn't illuminate how relative (as opposed to absolute) forecasting (Mathieu \& Gosling, 2012) might relate to situation selection success. Our exploratory analyses likewise suggest that our ways of indexing affective forecasting error might still merit further parsimony.

\section{General Discussion}

The overall aim of these studies was to ascertain whether affective forecasting ability is a resource for situation selection, and, if so, whether age moderated the relation between the two variables. Although neither Study 1 nor Study 2 confirmatory analyses provided support for this hypothesis, Study 2 exploratory analyses suggested that affective forecasting is associated with situation selection behaviors, though this association does not vary as a function of age.

\section{Links to Existing Literature}

The SOC-ER model posits that people might be apt to use situation selection if they have the ability to predict their emotional response (Urry \& Gross, 2010). The need for researching the potential association between affective forecasting and subsequent situation selection behaviors seems more evident than ever. Indeed, the field is becoming more interested in learning whether manipulating people's affective forecasting leads people to select situations that make them feel more positively (Quoidbach, Mikolajczak, \& Gross, 2015). Given what is known about emotional goals and preferences (e.g., Tamir, Ford, \& Ryan, 2013), however, it's quite possible that increasing affective forecasting ability more generally leads people to select situations that make them feel the way they want to feel, be it positive, negative, arousing, or some affective 
combination therein. On the other hand, if affective forecasting ability is only a resource for situation selection insofar as it serves to increase one's positive emotional outcomes, then affective forecasting might be a particularly salient resource for older adults because they might want to experience more positivity than negativity (Scheibe, \& Carstensen, 2010). It's been suggested that older adults might use situation selection because they want to avoid aversive physiological responding (Charles, 2010), and as such it may also be the case that affective forecasting is useful for older adults because they want to avoid feeling too aroused. Unlike in previous studies (e.g., Nielsen et al., 2008), Study 2 didn't find that older adults were more successful than younger adults at forecasting their affect, so perhaps the former argument should be given more credence. Thus, the conditions under which there may be an aging benefit to affective forecasting are unclear and deserve more consideration.

In addition to potential age differences in affective forecasting, there are also potential age differences in situation selection. Though the broader emotion and aging literature suggests that older adults might be more inclined to view and remember positive (relative to negative or neutral) stimuli (e.g., Mather \& Carstensen, 2005), recent work contradicts such a theory. Specifically, one study demonstrated that younger, middle-aged, and older adults selected equivalent ratios of valenced stimuli in the AE task, and exhibited mobile eye tracking behaviors that led to comparable emotional outcomes across all age groups (Isaacowitz et al., 2014). Study 2 likewise showed that younger and older adults watched similar ratios of valenced stimuli in the same task. Perhaps arousal, not valence, merits more attention in the aging literature (Sands \& Isaacowitz, 2016). Later comparisons could assess whether there were age differences in arousal in the AE, and, consequently, whether a more nuanced association between affective forecasting and situation selection can be observed. 


\section{Theoretical and Clinical Implications}

It seems plausible that people engage in affective forecasting and situation selection quite regularly, to varying degrees of success. Amongst other things, the Study 2 finding suggesting that fewer affective forecasting errors are associated with selecting fewer emotional relative to neutral situations could aid clinicians in recruiting and maintaining clients for various psychopathology treatments. Perhaps some individuals in need of treatment don't seek it out because they inaccurately overestimate how rejected, sad, or angry it would make them feel. If these individuals could be taught to forecast their emotions more accurately, they might be more likely to stay in treatment and remission. Thus, the association between affective forecasting and situation selection is directly applicable to treatment for psychopathology.

While the studies' clinical implications are important, the results hint that affective forecasting and situation selection are broadly related, and as such understanding how individuals generally use both of them on a daily basis is imperative. Affective forecasting and subsequent situation selection implicate not only socioemotional well-being but also decision making more generally. From a cognitive standpoint, they might further the understanding of predictive accuracy (Hoch, 1987), and might even provide avenues by which to enhance it. For example, recent evidence suggests that individuals induced to feel either disgust or embarrassment tend to anticipate avoiding sexual healthcare based on their perceived healthiness and prior sexual healthcare experiences (McCambridge \& Consedine, 2014). It's quite possible that individuals overestimate how much disgust or embarrassment they'll actually feel during routine appointments. Healthcare, sexual or otherwise, is very important, so maximizing individuals' access to it is paramount. If individuals could accurately forecast levels of disgust or embarrassment during routine healthcare procedures, their likelihood of selecting health- 
promoting situations would probably increase.

Affective forecasting might also play a role in how individuals choose to interact with others in a given situation. Interestingly, people's ability to appraise how other people feel might also influence their own affective forecasts and subsequent situation selection behaviors. Recent evidence suggests that individuals are likely to use other people's emotional expressions to infer what the other person is thinking, by using people's emotional expressions as proxies for their intentions in the situation (de Melo, Carnevale, Read, \& Gratch, 2014). If an observer in a prisoner dilemma sees the person across from them smiling, they might infer that the displayer is smiling because they're trying to cheat the observer. The observer's inference of the displayer's intention might motivate the observer to forecast that they would feel negatively about being cheated, and might subsequently cause the observer to choose not to trust the displayer during the trial. Thus, affective forecasting ability and situation selection might play a role in both intrapersonal and interpersonal decision making.

\section{Directions for Future Research}

Perhaps the biggest drawback of the current set of studies is that they are correlational in nature. However, they nevertheless provide meaningful information that can be used to motivate future experimental inquiries. For instance, if some individuals who make fewer affective forecasting errors regulate their emotions somewhat differently than individuals who make more errors, then perhaps it is possible to manipulate individuals' affective forecasting ability to affect how they regulate their emotions. One could implement a training aimed at increasing individuals' affective forecasting ability over time and see whether training had any influence on their subsequent situation selection behaviors. Drawing from the metacognition literature might be 
especially useful here. After all, as in absolute affective forecasting, people tend to think that their memory performance is different than it actually was (Lichtenstein, Fischhoff, \& Phillips, 1982). Yet one could theoretically maximize both the control and monitoring of information relevant to future metacognition and memory (Nelson \& Narens, 1990). Since affective forecasting ability is a metacognitive process, maximizing the control and monitoring of information relevant to emotional situations might work to increase affective forecasting success, too. One could even make the forecasts very specifically applicable to the person in question (e.g., forecasting events likely to happen in a corporate office as opposed to those likely to happen to an elementary school child), give the person feedback on their forecasting success (or lack thereof), and see whether the person is able to self-correct their forecasting success over time. Thus, the studies presented herein might serve to motivate interventions tailored to increase affective forecasting ability within an externally-valid context.

Another open question these two studies leave unanswered is how affective forecasting success should be conceptualized, and whether different conceptualizations of forecasting are more likely to be related to situation selection than others. For example, it's possible that taking an absolute difference between actual and forecasted affect is too restrictive in capturing forecasting error. It might also be useful to compare associations between absolute affective forecasting and relative affective forecasting to situation selection (Mathieu \& Gosling, 2012). Such was not the focus of the present research, but it represents a meaningful avenue of research to explore.

\section{Conclusions}

The goals of the two presented studies were: 1) to establish an association between affective 
forecasting and situation selection, and 2) to demonstrate a possible age difference therein. Confirmatory analyses failed to reveal hypothesized relations. However, exploratory analyses in which we re-envisioned our operational definitions of both affective forecasting and situation selection hinted in the methodologically-stronger of our two studies that, irrespective of age, affective forecasting may be related to individuals' situation selection behaviors after all. 
Acknowledgements, avoiding identifying any of the authors prior to peer review

The authors thank Jack Biedermann, John Budrow, Carter Casey, Alice Chan, Kara Cochran, Phoebe Din, Melissa Dong, Obaid Farooqui, Emma Hayden, Walae Hayek, Melissa Hwang, Sarah Makhani, Chris Martin, Nishi Mehta, Jordan Meisel, Jacob Merrin, Sydney Peskin, Tori Powell, Rachel Ribakove, Clau Robles-Gil, Andrew Rogers, Anoushka Shahane, Rachel, Wahlert, Kayla Williamson, and Stephanie Yin for their help with data collection and processing. They likewise thank Sara K. Johnson for her advice on the confirmatory factor analyses.

Materials, data files, and analysis scripts for both studies can be found at https://osf.io/nxwm4.

This project was funded by a graduate student research grant awarded to the first author, as well as by the U.S. Army Natick Soldier Research, Development, and Engineering Center (BAA Contract W911QY-13C-0012). The views expressed in this article are solely those of the authors and do not reflect the official policies or positions of the Department of Army, the Department of Defense, or any other department or agency of the U.S. government. 


\section{References}

Ayton P., Pott A., \& Elwakili N. (2007). Affective forecasting: Why can't people predict their emotions? Thinking \& Reasoning, 13(1), 62-80. doi:10.1080/13546780600872726

Charles, S. (2010). Strength and vulnerability integration: A model of emotional well being across adulthood. Psychological Bulletin, 136(6), 1068-1091. doi:10.1037/a0021232

de Melo, C. M., Carnevale, P. J., Read, S. J., \& Gratch, J. (2014). Reading people's minds from emotion expressions in interdependent decision making. Journal of Personality and Social Psychology, 106(1), 73-88. doi:10.1037/a0034251

Gilbert, D. T. (2007). Stumbling on happiness. New York: Vintage Books.

Gilbert, D. T., Pinel, E. C., Wilson, T. D., Blumberg, S. J., \& Wheatley, T. P. (1998). Immune neglect: A source of durability bias in affective forecasting. Journal of Personality and Social Psychology, 75(3), 617-638. doi:10.1037/0022-3 514.75.3.617

Gross, J.J. (1998). The emerging field of emotion regulation: An integrative review. Review of General Psychology 2(3), 271-299. doi:10.1037/1089-2680.2.3.271

Gross, J. J., \& Thompson, R. A. (2007). Emotion regulation: Conceptual foundations. In J. J. Gross (Ed.), Handbook of emotion regulation (pp. 3-24). New York: Guilford Press.

Hoch, S. J. (1987). Perceived consensus and predictive accuracy: The pros and cons of projection. Journal of Personality and Social Psychology, 53(2), 221-234. doi: $10.1037 / 0022-3514.53 .2 .221$

Isaacowitz, D. M., Livingstone, K. M., Harris, J. A., \& Marcotte, S. L. (2015). Mobile 
eye tracking reveals little evidence for age differences in attentional selection for mood regulation. Emotion, 15(2), 151-161. doi:10.1037/emo0000037

Kirschbaum, C., Pirke, K. M., \& Hellhammer, D. H. (1993). The 'Trier Social Stress Test'-a tool for investigating psychobiological stress responses in a laboratory setting. Neuropsychobiology, 28(1-2), 76-81. doi:10.1159/000119004

Kudielka, B. M., Buske-Kirschbaum, A., Hellhammer, D. H., \& Kirschbaum, C. (2004). Differential heart rate reactivity and recovery after psychosocial stress (TSST) in healthy children, younger adults, and elderly adults: the impact of age and gender. International Journal of Behavioral Medicine, 11(2), 116-121. doi:10.1207/s15327558ijbm1102_8

Larsen, J. T., Norris, C. J., McGraw, A. P., Hawkley, L. C., \& Cacioppo, J. T. (2009). The evaluative space grid: A single-item measure of positivity and negativity. Cognition and Emotion, 23(3), 453-480. doi:10.1080/02699930801994054

Lichtenstein, S., Fischhoff, B., \& Phillips, L. (1982). Calibration of probabilities: The state of the art to 1980. D. Kahneman, P. Slovic, and A. Tverski (Eds.) Judgement under uncertainty: Heuristics and biases.

Livingstone, K. M., \& Isaacowitz, D. M. (2015). Situation selection and modification for emotion regulation in younger and older adults. Social Psychological and Personality Science, 6(8), 904-910.doi:10.1177/1948550615593148

Mather, M., \& Carstensen, L. L. (2005). Aging and motivated cognition: The positivity effect in attention and memory. Trends in Cognitive Sciences, 9(10), 496-502. doi:10.1016/j.tics.2005.08.005

Mathieu, M. T., \& Gosling, S. D. (2012). The accuracy or inaccuracy of affective 
forecasts depends on how accuracy is indexed: A meta-analysis of past studies. Psychological Science, 23(2), 161-162. doi:10.1177/0956797611427044

McCambridge, S. A. \& Consdeine, N. S. (2014). For whom the bell tolls:

Experimentally-manipulated disgust and embarrassment may cause anticipated sexual healthcare avoidance among some people. Emotion, 14(2), 407-415. doi:10.1037/a0035209

Murphy, N. A., \& Isaacowitz, D. M. (2008). Preferences for emotional information in older and younger adults: A meta-analysis of memory and attention tasks. Psychology and Aging, 23(2), 263-286. doi:10.1037/0882-7974.23.2.263

Muthén, L.K., \& Muthén, B.O. (1998-2015). Mplus user's guide. Seventh edition. Los Angeles, CA: Muthén \& Muthén.

Nelson, T. O., \& Narens, L. (1990). Metamemory: A theoretical framework and new findings. Psychology of Learning and Motivation, 26, 125-173. doi:10.1016/S0079$7421(08) 60053-5$

Nielsen, L., Knutson, B., and Carstensen, L. L. (2008). Affect dynamics, affective forecasting, and aging. Emotion, 8(3), 318-330. doi:10.1037/1528-3542.8.3.318

Opitz, P. C., Gross, J. J., \& Urry, H. L. (2012). Selection, optimization, and compensation in the domain of emotion regulation: Applications to adolescence, older age, and major depressive disorder. Social and Personality Psychology Compass, 6(2), 142-155. doi:10.1111/j.1751-9004.2011.00413.x

Pearmana, A., Andreoletti, C., \& Isaacowitz, D. (2010). Sadness prediction and response: Effects of age and agreeableness. Aging and Mental Health, 14(3), 355-363. doi:10.1080/13607860903292586 
Quoidbach, J., Mikolajczak, M., \& Gross, J. J. (2015). Positive interventions: An emotion regulation perspective. Psychological Bulletin, 141(3), 655-693. doi:10.1037/a0038648

Rovenpor, D. R., Skogsberg, N.J., and Isaacowitz, D. M. (2013). The choices we make: An examination of situation selection in younger and older adults. Psychology and Aging, 28(2), 365-376. doi:10.1037/a0030450

Sands, M., Garbacz, A., \& Isaacowitz. D.M. (2016). Just change the channel? Studying effects of age on emotion regulation using a TV watching paradigm. Social Psychological and Personality Science, 7, 788-795.

Sands, M., \& Isaacowitz, D. M. (2016). Situation selection across adulthood: the role of arousal. Cognition and Emotion, 1-8.

Scheibe, S., \& Carstensen, L. L. (2010). Emotional aging: Recent findings and future trends. The Journals of Gerontology Series B: Psychological Sciences and Social Sciences, 1-10. doi:10.1093/geronb/gbp132

Sheppes, G., Scheibe, S., Suri, G., \& Gross, J.J. (2011). Emotion-regulation choice. Psychological Science, 22(11), 1391-1396. doi:10.1177/0956797611418350

Sieff, E. M., Dawes, R. M., \& Loewenstein, G. (1999). Anticipated versus actual reaction to HIV test results. The American Journal of Psychology, 112(2), 297-311. doi: $10.2307 / 1423355$

Tamir, M., Ford, B. Q., \& Ryan, E. (2013). Nonconscious goals can shape what people want to feel. Journal of Experimental Social Psychology, 49(2), 292-297. doi:10.1016/j.jesp.2012.11.009

Tamir, M., John, O. P., Srivastava, S., \& Gross, J. J. (2007). Implicit theories of 
emotion: Affective and social outcomes across a major life transition. Journal of Personality and Social Psychology, 92(4), 731. doi:10.1037/0022-3514.92.4.731

Urry, H. L., \& Gross, J. J. (2010). Emotion regulation in older age. Current Directions in Psychological Science, 19(6), 352-357. doi:10.1177/0963721410388395

Vujović, L., Opitz, P. C., Birk, J. L., \& Urry, H. L. (2014). Cut! That's a wrap: Regulating negative emotion by ending emotion-eliciting situations. Frontiers in Psychology, 5, 165. doi:10.3389/fpsyg.2014.00165 
Table 1. Sample Demographic Information for Study 1.

Mean age in years $(S D)$

$19.15(1.71)$

Gender

Male

$32.1 \%$

Female

$66 \%$

Did not report

$1.9 \%$

Ethnicity

Hispanic or Latino

$5.7 \%$

Not Hispanic or Latino

$92.5 \%$

Did not report

$1.9 \%$

Race

American Indian or Alaskan Native $\quad 1.9 \%$

Asian

$20.8 \%$

Black or African American

$5.7 \%$

Native Hawaiian or Other Pacific Islander

$0 \%$

White

$81.1 \%$

Did not report

$1.9 \%$

Educational attainment

High school diploma or equivalent

$22.6 \%$

Some college

$71.7 \%$

College diploma

$1.9 \%$

Some graduate school

$1.9 \%$

Did not report

$1.9 \%$ 
Table 2. Key forecasting and situation selection variable information for Study 1.

\begin{tabular}{|c|c|}
\hline & $M(S D)$ \\
\hline \multicolumn{2}{|l|}{$\begin{array}{l}\text { Absolute affective forecasting } \\
\text { error }\end{array}$} \\
\hline Negative & $.51(.54)$ \\
\hline Positive & $.56(.56)$ \\
\hline Arousal & $.56(.48)$ \\
\hline \multicolumn{2}{|l|}{$\begin{array}{l}\text { Situation selection videos } \\
\text { watched }\end{array}$} \\
\hline Total negative & $1.40(.72)$ \\
\hline Total neutral & $1.45(.72)$ \\
\hline Total positive & $1.45(.72)$ \\
\hline Negative-to-neutral & $.76(.63)$ \\
\hline Positive-to-neutral & $.81(.65)$ \\
\hline
\end{tabular}
divide by zero, these participants do not have any ratio scores. 
Table 3. Summary of regression analyses for variables predicting positive-to-neutral and negative-to-neutral videos watched in the situation selection task in Study 1.

\begin{tabular}{ccccccc}
\hline & \multicolumn{3}{c}{ Positive-to-Neutral } & \multicolumn{3}{c}{ Negative-to-Neutral } \\
\hline & $B$ & $S E B$ & $\beta$ & $B$ & SE B & $\beta$ \\
\hline $\begin{array}{c}\text { Absolute } \\
\text { forecasting }\end{array}$ & .37 & .21 & .32 & -.15 & -.13 & -.77 \\
$\begin{array}{c}\text { error-positive } \\
\text { Absolute }\end{array}$ & -.25 & .20 & -.21 & .27 & .23 & 1.49 \\
$\begin{array}{c}\text { forecasting } \\
\text { error-negative }\end{array}$ & & & & & & \\
$\quad \begin{array}{l}\text { Absolute } \\
\text { forecasting }\end{array}$ & -.22 & .21 & -.17 & $-.44^{*}$ & -.33 & -2.32 \\
error-arousal & & & & & \\
$\quad R^{2}$ & & .07 & & & .17 & \\
$F$ for $R^{2}$ & 1.2 & & & & & \\
\hline
\end{tabular}

Note: ${ }^{*} p<.05$ 
Table 4. Pearson-product moment correlation coefficients between absolute affective forecasting error and situation selection behaviours in Study 1 .

\begin{tabular}{|c|c|c|c|c|c|c|c|c|}
\hline & $\begin{array}{l}\text { Forecasting } \\
\text { Error- } \\
\text { Positive }\end{array}$ & $\begin{array}{c}\text { Forecasting } \\
\text { Error- } \\
\text { Negative }\end{array}$ & $\begin{array}{c}\text { Forecasting } \\
\text { Error- } \\
\text { Arousal }\end{array}$ & $\begin{array}{l}\text { Positive } \\
\text { Videos } \\
\text { Watched }\end{array}$ & $\begin{array}{l}\text { Negative } \\
\text { Videos } \\
\text { Watched }\end{array}$ & $\begin{array}{c}\text { Neutral } \\
\text { Videos } \\
\text { Watched }\end{array}$ & $\begin{array}{c}\text { Positive-to- } \\
\text { Neutral } \\
\text { Videos } \\
\text { Watched }\end{array}$ & $\begin{array}{c}\text { Negative-to- } \\
\text { Neutral } \\
\text { Videos } \\
\text { Watched }\end{array}$ \\
\hline $\begin{array}{c}\text { Forecasting } \\
\text { Error- } \\
\text { Positive }\end{array}$ & - & & & & & & & \\
\hline $\begin{array}{c}\text { Forecasting } \\
\text { Error- } \\
\text { Negative }\end{array}$ & $.53^{* *}$ & - & & & & & & \\
\hline $\begin{array}{c}\text { Forecasting } \\
\text { Error- } \\
\text { Arousal }\end{array}$ & $.40^{* *}$ & .11 & - & & & & & \\
\hline $\begin{array}{l}\text { Positive } \\
\text { Videos } \\
\text { Watched }\end{array}$ & .07 & $-.32^{*}$ & .18 & - & & & & \\
\hline $\begin{array}{l}\text { Negative } \\
\text { Videos } \\
\text { Watched }\end{array}$ & -.14 & -.01 & -.16 & -.16 & - & & & \\
\hline $\begin{array}{c}\text { Neutral } \\
\text { Videos } \\
\text { Watched }\end{array}$ & -.01 & $.24^{\dagger}$ & -.19 & $0.33^{*}$ & -.21 & - & & \\
\hline $\begin{array}{c}\text { Positive-to- } \\
\text { Neutral } \\
\text { Videos } \\
\text { Watched }\end{array}$ & .14 & -.06 & -.06 & $.51^{* *}$ & $-.29^{*}$ & .02 & - & . \\
\hline $\begin{array}{c}\text { Negative-to- } \\
\text { Neutral } \\
\text { Videos } \\
\text { Watched }\end{array}$ & -.14 & .13 & $-.36^{* *}$ & -.25 & $.55^{* *}$ & .09 & $.38^{* *}$ & - \\
\hline
\end{tabular}

Note: $* p<.05, * * p<.01$ 
Table 5. Sample demographic information for Study 2.

\begin{tabular}{|c|c|c|}
\hline & Younger Adults & Older Adults \\
\hline Mean age in years $(S D)$ & $18.96(1.39)$ & $69.40(3.63)$ \\
\hline \multicolumn{3}{|l|}{ Gender } \\
\hline Male & $44.4 \%$ & $32 \%$ \\
\hline Female & $55.6 \%$ & $68 \%$ \\
\hline \multicolumn{3}{|l|}{ Ethnicity } \\
\hline Hispanic or Latino & $13 \%$ & $2 \%$ \\
\hline Not Hispanic or Latino & $83.3 \%$ & $98 \%$ \\
\hline Did not report & $3.7 \%$ & $0 \%$ \\
\hline \multicolumn{3}{|l|}{ Race } \\
\hline American Indian or Alaskan Native & $0 \%$ & $0 \%$ \\
\hline Asian & $35.2 \%$ & $4 \%$ \\
\hline Black or African American & $5.6 \%$ & $6 \%$ \\
\hline Native Hawaiian or Other Pacific Islander & $1.9 \%$ & $0 \%$ \\
\hline White & $59.3 \%$ & $88 \%$ \\
\hline Did not report & $1.9 \%$ & $2 \%$ \\
\hline \multicolumn{3}{|l|}{ Educational attainment } \\
\hline High school diploma or equivalent & $44.4 \%$ & $4 \%$ \\
\hline Some college & $53.7 \%$ & $8 \%$ \\
\hline College diploma & $1.9 \%$ & $28 \%$ \\
\hline Some graduate school & $0 \%$ & $8 \%$ \\
\hline Graduate degree & $0 \%$ & $52 \%$ \\
\hline
\end{tabular}


Table 6. Key forecasting and situation selection variable information by age for Study 2 .

\begin{tabular}{|c|c|c|c|c|c|}
\hline & \multicolumn{2}{|c|}{ Younger Adults } & Older Adults & \multirow{2}{*}{$\begin{array}{c}p \\
\text { value for } \\
\text { the age } \\
\text { difference }\end{array}$} & \multirow{2}{*}{$\begin{array}{c}\text { Cohen's } \\
d \text { for the } \\
\text { age } \\
\text { difference }\end{array}$} \\
\hline & $N$ & $M(S D)$ & $N \quad M(S D)$ & & \\
\hline \multicolumn{6}{|l|}{$\begin{array}{l}\text { Absolute affective forecasting } \\
\text { error }\end{array}$} \\
\hline Negative & 54 & $1.46(.69)$ & $501.62(.64)$ & .23 & -.24 \\
\hline Positive & 54 & $1.31(.51)$ & $501.33(.53)$ & .81 & -.05 \\
\hline Arousal & 54 & $1.09(.53)$ & $501.11(.49)$ & .79 & -.05 \\
\hline \multicolumn{6}{|l|}{$\begin{array}{l}\text { Situation selection videos } \\
\text { watched }\end{array}$} \\
\hline Total negative & 54 & $1.48(.91)$ & $501.30(1.04)$ & .34 & .19 \\
\hline Total neutral & 54 & $1.56(.93)$ & $501.66(.69)$ & .52 & -.12 \\
\hline Total positive & 54 & $2.96(.78)$ & $503.04(.83)$ & .63 & -.01 \\
\hline Negative-to-neutral & 47 & $.97(.83)$ & $481.01(1.04)$ & .83 & -.04 \\
\hline Positive-to-neutral & 47 & $1.99(1.12)$ & $481.97(.88)$ & .92 & .02 \\
\hline
\end{tabular}

Note: As a reminder, some participants did not watch any neutral videos. Since one cannot divide by zero, these participants do not have any ratio scores. 
Table 7. Summary of regression analyses for variables predicting positive-to-neutral and negative-to-neutral videos watched in the situation selection task in Study 2.

\begin{tabular}{ccccccc}
\hline & \multicolumn{3}{c}{ Positive-to-Neutral } & \multicolumn{3}{c}{ Negative-to-Neutral } \\
\hline & $B$ & $S E B$ & $\beta$ & $B$ & SE B & $\beta$ \\
\hline $\begin{array}{c}\text { Absolute } \\
\text { forecasting } \\
\text { error-positive }\end{array}$ & .17 & .22 & .09 & .34 & .22 & .19 \\
$\begin{array}{c}\text { Absolute } \\
\text { forecasting }\end{array}$ & .02 & .19 & .02 & .09 & .19 & .07 \\
$\begin{array}{c}\text { error-negative } \\
\text { Absolute }\end{array}$ & .48 & .29 & .24 & -.22 & .28 & -.12 \\
$\begin{array}{c}\text { forecasting } \\
\text { error-arousal }\end{array}$ & & & & & & \\
$R^{2}$ & & & & & .03 & \\
$F$ for $R^{2}$ & & .09 & & & .86 & \\
\hline
\end{tabular}

Note: $* p<.05$ 
Table 8. Pearson-product moment correlation coefficients between absolute affective forecasting error and situation selection behaviors in Study 2.

\begin{tabular}{|c|c|c|c|c|c|c|c|c|}
\hline & $\begin{array}{c}\text { Forecasting } \\
\text { Error- } \\
\text { Positive }\end{array}$ & $\begin{array}{c}\text { Forecasting } \\
\text { Error- } \\
\text { Negative }\end{array}$ & $\begin{array}{c}\text { Forecasting } \\
\text { Error- } \\
\text { Arousal }\end{array}$ & $\begin{array}{c}\text { Positive } \\
\text { Videos } \\
\text { Watched }\end{array}$ & $\begin{array}{l}\text { Negative } \\
\text { Videos } \\
\text { Watched }\end{array}$ & $\begin{array}{c}\text { Neutral } \\
\text { Videos } \\
\text { Watched }\end{array}$ & $\begin{array}{c}\text { Positive-to- } \\
\text { Neutral } \\
\text { Videos } \\
\text { Watched }\end{array}$ & $\begin{array}{c}\text { Negative- } \\
\text { to-Neutral } \\
\text { Videos } \\
\text { Watched }\end{array}$ \\
\hline $\begin{array}{c}\text { Forecasting } \\
\text { Error- } \\
\text { Positive }\end{array}$ & - & & & & & & & \\
\hline $\begin{array}{l}\text { Forecasting } \\
\text { Error- } \\
\text { Negative }\end{array}$ & .15 & - & & & & & & \\
\hline $\begin{array}{c}\text { Forecasting } \\
\text { Error- } \\
\text { Arousal }\end{array}$ & $.46^{* *}$ & $.64^{* *}$ & - & & & & & \\
\hline $\begin{array}{l}\text { Positive } \\
\text { Videos } \\
\text { Watched }\end{array}$ & .09 & .18 & $.29^{* *}$ & - & & & & \\
\hline $\begin{array}{c}\text { Negative } \\
\text { Videos } \\
\text { Watched }\end{array}$ & $.17^{\dagger}$ & -.01 & -.02 & $-.59^{* * *}$ & - & & & \\
\hline $\begin{array}{c}\text { Neutral } \\
\text { Videos } \\
\text { Watched }\end{array}$ & $-.29^{* *}$ & -.16 & $-.26^{* *}$ & $-.28^{* *}$ & $-.61^{* *}$ & - & & \\
\hline $\begin{array}{c}\text { Positive-to- } \\
\text { Neutral } \\
\text { Videos } \\
\text { Watched }\end{array}$ & .19 & .18 & $.29^{* *}$ & $.64^{* *}$ & -.02 & $-.78^{* *}$ & - & \\
\hline $\begin{array}{l}\text { Negative- } \\
\text { to-Neutral } \\
\text { Videos } \\
\text { Watched }\end{array}$ & .15 & .16 & .01 & $-.47^{* *}$ & $.92^{* *}$ & $-.71^{* *}$ & $.29^{* *}$ & - \\
\hline
\end{tabular}

Note: $* p<.05, * * p<.01$ 
Table 9a. Model fit information and parameter estimates from exploratory analyses examining the association between affective forecasting error and situation selection behaviors in Study 2.

\begin{tabular}{|c|c|c|c|c|c|c|c|c|}
\hline \multirow[b]{2}{*}{ Model } & \multicolumn{3}{|c|}{ Selected Model Fit Information } & \multirow[b]{2}{*}{ Variable } & \multirow[b]{2}{*}{$B$} & \multirow[b]{2}{*}{$S E B$} & \multirow[b]{2}{*}{$B$} & \multirow[b]{2}{*}{$S E B$} \\
\hline & $\begin{array}{c}\text { Free } \\
\text { Parameters }\end{array}$ & AIC & $\begin{array}{l}\text { Sample- } \\
\text { Size } \\
\text { Adjusted } \\
\text { BIC }\end{array}$ & & & & & \\
\hline \multirow{12}{*}{1} & \multirow{12}{*}{29} & \multirow{12}{*}{2516.92} & \multirow{12}{*}{2501.99} & Affective forecasting error latent criterion variable & & & & \\
\hline & & & & Indicators & \multicolumn{2}{|c|}{ Factor Loadings } & & \\
\hline & & & & Absolute forecasting error-Positive video, negative & $.815^{* *}$ & .197 & & \\
\hline & & & & Absolute forecasting error-Positive video, positive & $-.368^{* *}$ & .155 & & \\
\hline & & & & Absolute forecasting error-Negative video, negative & -.011 & .076 & & \\
\hline & & & & Absolute forecasting error-Negative video, positive & $.401^{*}$ & .165 & & \\
\hline & & & & Absolute forecasting error-Neutral video, negative & $.273^{*}$ & .123 & & \\
\hline & & & & Absolute forecasting error-Neutral video, positive & .203 & .164 & & \\
\hline & & & & Between-Subjects Predictors & \multicolumn{2}{|c|}{ Hedonic Motivation } & \multicolumn{2}{|c|}{ Emotional Approach } \\
\hline & & & & Affective forecasting error & -.036 & .181 & .460 & .349 \\
\hline & & & & Age & .132 & .154 & -.183 & .235 \\
\hline & & & & Affective forecasting error*Age & -.229 & .183 & -.481 & .360 \\
\hline \multirow{8}{*}{2} & \multirow{8}{*}{17} & \multirow{8}{*}{1245.30} & \multirow{8}{*}{1236.55} & Affective forecasting error latent criterion variable & & & & \\
\hline & & & & Indicators & \multicolumn{2}{|c|}{ Factor Loadings } & & \\
\hline & & & & Absolute forecasting error-Average negative & $.189^{\dagger}$ & .111 & & \\
\hline & & & & Absolute forecasting error-Average positive & $.257^{*}$ & .115 & & \\
\hline & & & & Between-Subjects Predictors & \multicolumn{2}{|c|}{ Hedonic Motivation } & \multicolumn{2}{|c|}{ Emotional Approach } \\
\hline & & & & Affective forecasting error & -.176 & .579 & $1.438^{* *}$ & .510 \\
\hline & & & & Age & .136 & .156 & -.209 & .224 \\
\hline & & & & Affective forecasting error*Age & -.184 & .419 & -.572 & .354 \\
\hline & & & & Affective forecasting error average variable & & & & \\
\hline \multirow{4}{*}{3} & \multirow{4}{*}{11} & \multirow{4}{*}{872.69} & \multirow{4}{*}{867.03} & Between-Subjects Predictors & \multicolumn{2}{|c|}{ Hedonic Motivation } & \multicolumn{2}{|c|}{ Emotional Approach } \\
\hline & & & & Affective forecasting error & .068 & .379 & $1.544^{* *}$ & .501 \\
\hline & & & & Age & .540 & .589 & .341 & .752 \\
\hline & & & & Affective forecasting error*Age & -.290 & .379 & -.398 & .501 \\
\hline
\end{tabular}

Note: $* p<.05, * * p<.01, \dagger p<.1$ 
Table $9 b$

Model Fit Information and Parameter Estimates from Exploratory Analyses Examining the Association Between Affective Forecasting Error and Situation Selection Behaviors in Study 1

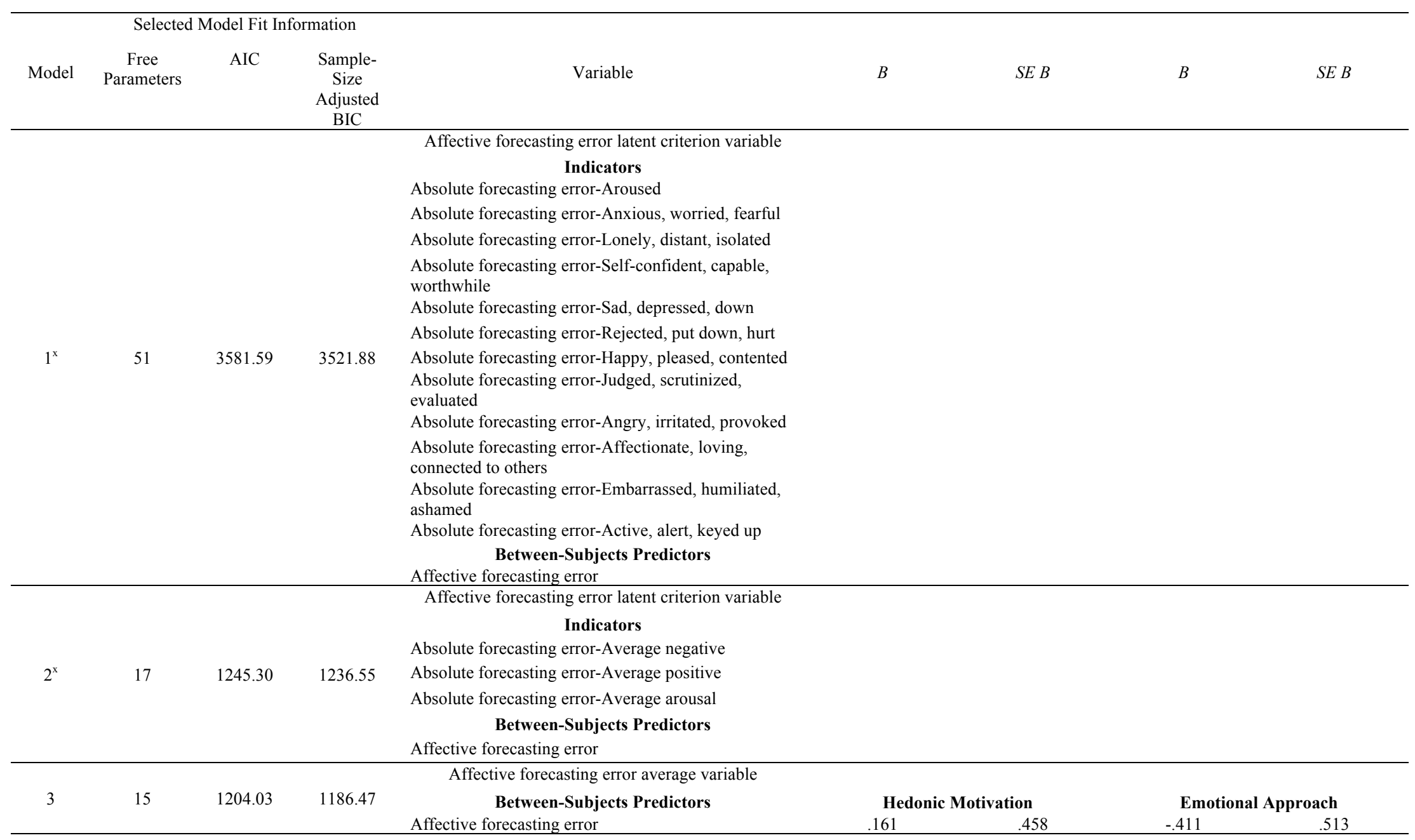

Note: ${ }^{*} p<.05, * * p<.01, \dagger p<.1 ; \mathrm{x}$ denotes an insufficient number of free parameters for confident model estimation 
Figure 1. An example of one configuration of video thumbnails participants viewed during the Study 1 situation selection task. Each column corresponds to the videos' valence (negative, neutral, or positive), and the number of asterisks above each item corresponds to how arousing the video is. One asterisk is indicative of relatively low arousal, whereas two asterisks are indicative of relatively high arousal. If participants wanted to view a high-arousal positive video they would select the thumbnail in the bottom right-hand corner, which is highlighted in blue.

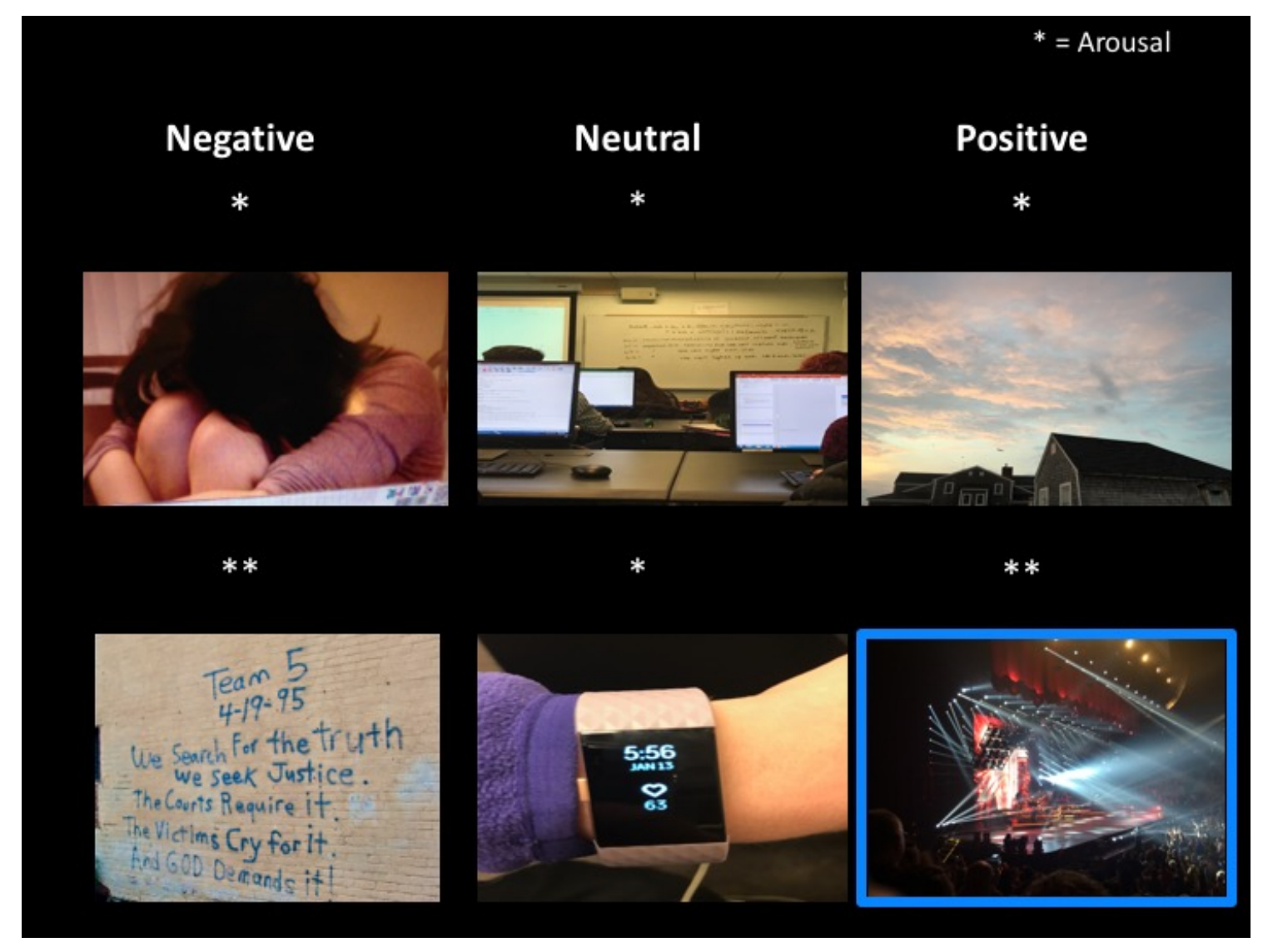


Figure 2. An example of one configuration of video information participants viewed during the Study 2 situation selection task. Each column corresponds to the videos' valence (negative, neutral, or positive), and the number of asterisks above each item corresponds to how arousing the video is. One asterisk is indicative of relatively low arousal, whereas two asterisks are indicative of relatively high arousal. The number of videos remaining within each category is presented inside each box. If participants wanted to view one of the high-arousal positive videos they would select the box in the bottom right-hand corner, which is highlighted in pink.

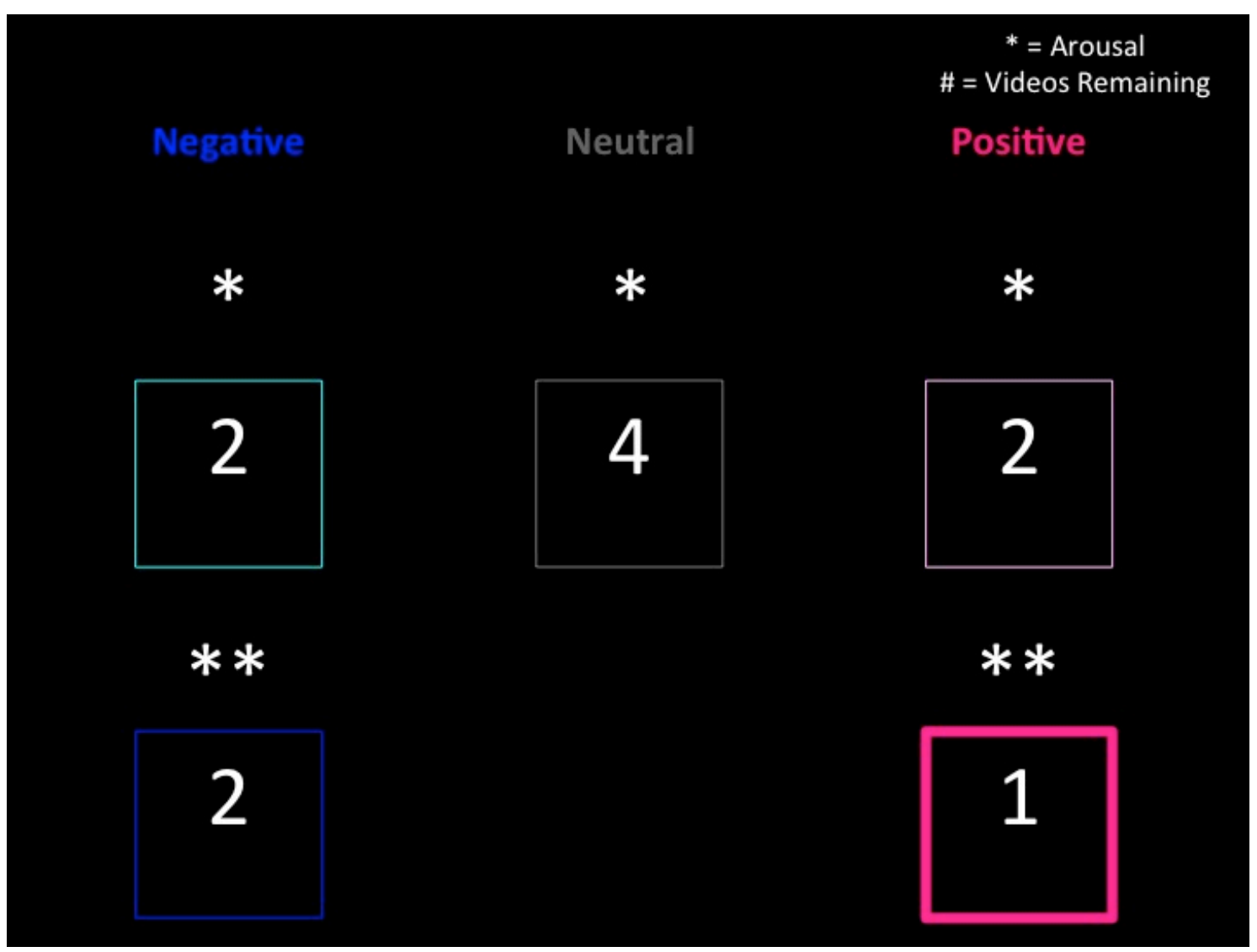


Figure 3. Scatter plots of the association between the affective forecasting error factor score and the difference of emotional and neutral videos participants watched during the situation selection task in Studies 1 and 2. In Study 1, there was no association between younger adults' affective forecasting error and the extent to which they watched more emotional (than neutral) videos. In Study 2, there was an association between affective forecasting error and the extent to which participants watched more emotional (than neutral) videos; but no age difference was found.
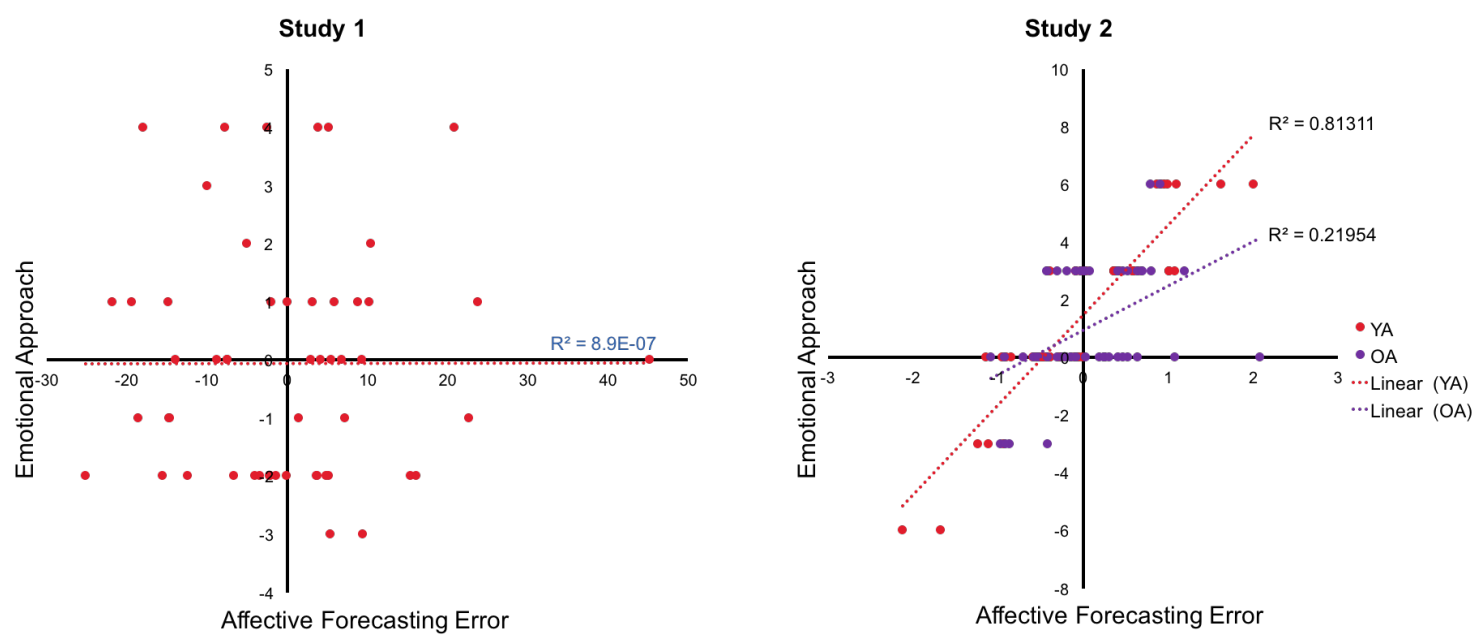


\section{Appendix}

\section{Descriptions Provided in Affective Forecasting Tasks}

\section{Study 1}

For the interview speech task, participants read the following:

Later in this session we will conduct a test of your verbal communication ability. You will be given 3 minutes to prepare a 5-minute interview talk for a job position in a relevant area of interest. The content of your speech, your body language, and the persuasiveness of your argument will be evaluated by the lab's researchers.

Relatedly, for the mental arithmetic task, participants read the following:

Later in this session we will have you perform a task to verify your alertness. The task is quite easy and most people don't have a problem with it. You will count out loud backwards from 2,223 in increments of 17. You will complete this task without using a pen and paper. If you miscalculate we will point out your mistake, and you will have to start over again.

\section{Study 2}

The descriptions participants read before making their forecasts for the positive, negative, and neutral video clips were "watching a video clip about a cute bear cub playing with a man", "watching a video clip about the reenactment of a real human shark attack", and "watching a video clip about what would hypothetically happen to the world without oxygen", respectively.

\section{Post-Task Questionnaires}

Emotion Regulation Strategies Questionnaire (ERS)

The ERS is an in-house, 20-item measure designed to ascertain the strategies individuals use when regulating their emotions. It is a task-specific measure that 
assessed the extent to which participants used specific emotion regulation strategies during the affective forecasting task and the situation selection task, respectively. Participants rated each item on a Likert scale $(1=$ not at all, $9=$ quite a bit $)$.

Difficulty, success, and effort

Participants' difficulty with, success on, and effort exerted in both the affective forecasting task and the situation selection task was assessed with this 9-item in-house measure. Participants rated each item on a Likert scale $(1=$ not at all, $10=$ extremely $)$.

\section{Study $1 \& 2$ Trait Questionnaires}

A wide battery of trait questionnaires was administered to participants at the end of the laboratory sessions (i.e., after participants had completed any affective forecasting or situation selection tasks and their respective post-task questionnaires) for both Studies 1 and 2.

\section{Affective style}

The 20-item Affective Style Questionnaire (ASQ; Hofmann \& Kashdan, 2010) was administered to ascertain how individuals tend to regulate their emotions. Participants rated each item on a Likert scale $(1=$ not true of me, $5=$ extremely true of me $)$. It examines three basic regulatory tendencies: concealing, adjusting, and tolerating. Stress

Trait levels of stress were assessed using the Life Experiences Survey (LES; Sarason, Johnson, \& Siegel, 1978). The LES is a 50-item measure that assesses the number of common stressors individuals experienced over the past 4 months, as well as the perceived impact each of those stressors had on the individual $(-3=$ extremely negative, $+3=$ extremely positive).

Sleep assessment 
Participants were asked to report about their sleep the night before they came into the laboratory for the study across 10 different items. Topics of interest include when the participant went to sleep, whether they woke up during the night, and when they woke up in the morning.

Menstrual cycle assessment

8 self-report items were given to all female participants to ascertain important information about their menstrual cycles. Topics of interest include typical cycle duration, whether or not they've ever experienced amenorrhea, and information about their contraceptive usage.

\section{Global health}

At the end of the trait questionnaire battery participants were asked to rate their overall health and quality of life. Participants made ratings on a Likert scale $(1=$ excellent, $5=$ poor).

\section{Study 2 Trait Questionnaires}

\section{Recent life stress}

To help further mask the importance of the forecasts, participants also made forecasts about how they would feel during a series of commonplace stressors. These lure items were derived from the Survey of Recent Life Experiences scale (Kohn \& Macdonald, 1992) and assesses prototypical life stressors. Participants were asked to indicate whether they had experienced a given stressor over the course of the past month $(1=$ not all part of my life, 4 = very much part of my life).

Emotional preferences and experiences

In order to assess both which particular emotions people generally want to feel and the extent to which they actually feel them, the Affect Valuation Index (AVI; Tsai, Knutson, \& Fung, 2006) was administered to participants. The adapted AVI is a 30- 
emotion measure that asks participants to rate the extent to which they ideally want to feel, think they will feel, and actually feel 30 different affective states (e.g., euphoric, fearful, aroused $)$ over the course of the week $(1=$ never, $5=$ all the time $)$. They filled out this questionnaire online after they made their affective forecasts on day 1.

\section{Psychological health outcomes}

In an attempt to further illuminate individual-difference relations between affective forecasting ability, situation selection behavior, and psychological health, measures of participants' depressive and anxiety symptoms were administered at various time points throughout Study 2, as described in the paragraphs below.

Depressive symptoms. To measure depressive symptoms the Beck Depressive Inventory-II (BDI-II; Beck, Steer, \& Brown, 1996) was used. The BDI is a 21-item measure of various depressive syptoms $(0=$ no symptoms, 3 = high symptomatology $)$. Though one's score on this measure does not in and of itself constitute a clinical diagnosis of Major Depressive Disorder (MDD), it does serve as a suitable proxy for assessing general depressive symptomatology within the population (Beck, Steer, \& Carbin, 1988). The scale asks participants to report about their symptoms of sadness, guilt, irritation, and so forth. One item concerns suicidiality, but it was omitted from this study, as the scale here is meant to serve as an individual difference measure of psychological health, not as a means of assessing MDD. The BDI-II was administered to participants in the laboratory after the affective forecasting task on day 7 .

Anxiety symptoms. To assess general anxiolytic symptoms the trait version of the State Trait Inventory for Cognitive and Somatic Anxiety (STICSA; Grös, Antony, Sims, \& McCabe, 2007) was administered. The STICSA is a 21-item measure that assesses the extent to which one worries (e.g., "I think that the worst will happen") and feels physically anxious (e.g., "My heart beats fast"). Participants rated the extent to which 
they generally feel each of these symptoms $(1=$ not at all, $4=$ very much so $)$ after the affective forecasting task on day 7.

\section{Peripheral Physiology}

Peripheral physiological data were obtained using a MP150 system (Biopac, Goleta, CA) and processed using ANSLAB (Wilhelm \& Peyk, 2005). It was collected with the primary goal of assessing whether or not the stress induction used in the situation selection task was affective.

Electrocardiography (ECG)

Electrocardiography was used to measure heart rate (HR), which is dually innervated by the sympathetic and parasympathetic branches of the autonomic nervous system. In event-related paradigms involving passive viewing of unpleasant pictures, HR exhibits an initial, parasympathetically-mediated deceleration (Bradley \& Lang, 2007). Two disposable $\mathrm{Ag} / \mathrm{AgCl}$ electrodes pre-gelled with 7\% chloride gel $(1 \mathrm{~cm}$ circular contact area) were placed under the left and right collar bones on the chest after swabbing with an alcohol prep pad and then gently debrading using an electrode prep pad. ECG was acquired continuously at $1000 \mathrm{~Hz}$.

Offline, the ECG signal was downsampled to $400 \mathrm{~Hz}$ and bandpass-filtered from .5 to $40 \mathrm{~Hz}$. Interbeat interval (IBI) series were created by identifying R-spikes using automated ANSLAB algorithms. R-spikes that were not detected automatically, thus leading to an erroneously long period between successive R-spikes, were marked for inclusion by hand. Similarly, R-spikes that were identified incorrectly, thus leading to an erroneously short period between successive R-spikes, were removed by hand. Following such artifact correction, the IBI series was converted to heart rate in beats per minute. Heart rate data were decimated to $10 \mathrm{~Hz}$ and then smoothed with a 1-s prior moving average filter. 
Skin conductance level (SCL)

Skin conductance was selected as a pure measure of sympathetic activation of the autonomic nervous system. Two disposable $\mathrm{Ag} / \mathrm{AgCl}$ electrodes pre-gelled with $0.5 \%$ chloride isotonic gel $(1 \mathrm{~cm}$ circular contact area) were attached to the distal phalanges of the index and middle fingers on the non-dominant hand. One electrode was attached to the back of the neck to serve as a ground. SCL was recorded with DC coupling and constant voltage electrode excitation at $31.25 \mathrm{~Hz}$ (sensitivity $=.7 \mathrm{nS}$ ). Offline, the SCL data were smoothed with a $1 \mathrm{~Hz}$ low-pass filter, decimated to $10 \mathrm{~Hz}$.

Corrugator electromyography

Corrugator electromyography was selected as an index of facial expressive behavior, even that which is not overtly observable. It is sensitive to stimulus valence, exhibiting greater activity in response to unpleasant stimuli and lower activity in response to pleasant stimuli (Bradley \& Lang, 2007). Two 4-mm Ag/AgCl electrodes were placed in bipolar configuration over the left eye per Fridlund and Cacioppo (1986). Corrugator electromyography was sampled at $2000 \mathrm{~Hz}$ and bandpass-filtered online $(5 \mathrm{~Hz}$ to $3 \mathrm{kHz}$; $60-\mathrm{Hz}$ notch filter on). Offline, data were resampled to $400 \mathrm{~Hz}$, rectified and smoothed with a 16-Hz low-pass filter, decimated to $4 \mathrm{~Hz}$, and smoothed with a 1-s prior moving average filter.

\section{Eye Tracking}

Bilateral eye-tracking data were unobtrusively collected using a Tobii T120 Eye Tracker (Danderyd, Sweden; sampled at $60 \mathrm{~Hz}$ ). Fixations were identified using the "Tobii fixation filter" algorithm. Areas of interest were determined a priori based on the type of information the participant was looking at on the screen-namely, information concerning valence and arousal. 